\title{
Políticas de la metamorfosis en Juan Rodolfo Wilcock
}

Politics of Metamorphosis in Juan Rodolfo Wilcock

Políticas da metamorfose em Juan Rodolfo Wilcock

\section{Karina Miller}

THE CALIFORNIA STATE UNIVERSITY, SAN MARCOS, ESTADOS UNIDOS

Profesora del Departamento de Español y Portugués en The California State University, San Marcos. PhD por la Universidad de California en Irvine. Ha publicado en revistas y antologías como Hispamérica, Revista Iberoamericana, Dissidences: Hispanic fournal of Theory and Criticism, A Contracorriente, La estela de Caicedo - volumen sobre Andrés Caicedo-, Miradas Críticas y el volumen Estar en el presente. Literatura y nación desde el bicentenario (editado por Enrique Cortez y Gwen Kirkpatrick). Su libro, titulado Escrituras impolíticas: anti-representaciones de la comunidad en fuan Rodolfo Wilcock, Osvaldo Lamborghini y Virgilio Piñera, es de próxima aparición en la colección Nuevo Siglo (Instituto Internacional de Literatura Iberoamericana). Correo electrónico: karinamillerı@gmail.com

\section{Artículo de reflexión}

Documento accesible en línea desde la siguiente dirección: http://revistas.javeriana.edu.co doi:10.11144/Javeriana.cl21-41.pmjr 


\section{Resumen}

Este trabajo explora cómo la representación de ciertas figuras y experiencias negativas en la narrativa de Juan Rodolfo Wilcock, funciona como desfamiliarización de la lógica de lo político definido, según Carl Schmitt, como el antagonismo amigo-enemigo. Desde esta perspectiva se analizan la figura de la metamorfosis, $y$ sus correlatos de la soledad y la estupidez, como afectos, experiencias y estados negativos que, por un lado, funcionan como críticas a la noción de comunidad y, por otro, vuelven imposible la lógica antagónica de lo político.

Palabras clave: política; metamorfosis; literatura; peronismo; comunidad

\section{Abstract}

This article explores how literary representation of certain figures and negative experiences in Juan Rodolfo Wilcock's narrative, works as a form of defamiliarization of the logic of the political that, according to Carl Schmitt, is defined as the antagonism between friend and foe. From this perspective I analyze the figure of metamorphosis, and its correlates of loneliness and stupidity, as affects, experiences and negative states that function both as a critique of the notion of community, and the antagonistic logic of the political.

Keywords: politics; metamorphosis; literature; peronism; community

\section{Resumo}

Este trabalho explora como a representação de certas figuras e experiências negativas na narrativa de Juan Rodolfo Wilcock funciona como desfamiliarização da lógica do político definido, segundo Carl Schmitt, como o antagonismo amigo-inimigo. Desde essa perspectiva analisam-se a figura da metamorfose e seus correlatos da soledade e a estupidez, como afetos, experiências e estados negativos que, por um lado, funcionam como críticas à noção de comunidade e, por outro, impossibilitam a lógica antagónica do político.

Palavras-chave: política; metamorfose; literatura; peronismo; comunidade 


\section{Metamorfosis}

Es imposible leer a Juan Rodolfo Wilcock (Argentina, 1919-Italia, 1978) sin tener en cuenta algunos datos fundamentales de su biografía: era antiperonista (perteneció al grupo de la revista Sur); partió para Italia en 1957, y escribió el resto de su obra en italiano. Si bien el contexto de producción de su obra argentina (en su mayoría poesía neorromántica) fue el primer gobierno peronista (1943-1955), en Italia continuó escribiendo, reescribiendo y traduciendo ciertos temas recurrentes en su escritura, relacionados con el peronismo, la Argentina y la dicotomía civilización o barbarie. ${ }^{1}$

En El libro de los monstruos (publicado póstumamente en Italia en 1978) Wilcock presenta una colección de seres que han sufrido metamorfosis varias, algunos transformados en objetos como un cenicero, por ejemplo, o un volcán en erupción, pero que siguen intentando o simulando cumplir sus funciones dentro de la comunidad y del núcleo familiar. Esta insistencia en la inutilidad e imposibilidad de la comunidad, pone en escena su cuestionamiento como proyecto político constituido en el antagonismo "nosotros-ellos". Desde esta perspectiva el peronismo, que ha sido identificado en la escritura de Wilcock por la crítica como un núcleo de enunciación y producción fundamentalmente antagónico, se vuelve un lugar absurdo desde donde se cuestiona el antagonismo de lo político per se.

Además de ser tropo de sus relatos, hay también una metamorfosis que se revela en la escritura misma, la cual transmuta de poesía neo-romántica (en los años cuarenta) a una prosa posterior irónica y paródica, en la cual se puede rastrear una insistencia en la representación de la política y de lo político como pura estupidez. Propongo, entonces, leer el tropo de la metamorfosis como anti-representación de ciertos paradigmas discursivos que fundamentan la comunidad imaginada del peronismo; de esta manera, las figuras de la metamorfosis, la soledad y la estupidez funcionan a contrapelo, respectivamente, de la retórica peronista del trabajo y del trabajador; de la idea de patria como origen de identidad, y del antagonismo amigo-enemigo como lógica bélica constitutiva de lo político y de la soberanía (Carl Schmitt). ${ }^{2}$ Sin embargo, mi lectura propone que la "absurdización" de la política

1 Su primer libro de poesía, Libro de poemas y canciones (1940), obtuvo el Premio Martín Fierro. Entre 1942 y 1944 dirige la revista literaria Verde Memoria, y entre 1945 y 1947 la revista Disco. En 1945 publica los libros de poesía Ensayos de poesía lírica y Persecución de las musas menores, y en 1946 Paseo Sentimental y Los hermosos días. En 1956 publica en colaboración con Silvina Ocampo una obra de teatro llamada Los traidores.

2 En The Concept of The Political, Schmitt define lo político como el antagonismo amigoenemigo, y la soberanía como la capacidad del Estado de identificar y exterminar físicamente al enemigo público: aquel que amenaza el propio estilo de vida. 
y lo político provoca un efecto búmerang, ya que la crítica al paradigma peronista produce una vuelta de tuerca que cuestiona al antagonismo de lo político en sí mismo, como estructura bélica significante y abstracta.

La metamorfosis origina una experiencia de extrañamiento y soledad profunda que transforma la subjetividad de los personajes y su consecuente manera de ver y relacionarse con el mundo. Si bien no implica un traslado espacial sino un cambio de forma, la transformación resulta en un distanciamiento crítico con el entorno (propia también, como se verá más adelante, del viaje) que interrumpe el discurso de la comunidad como totalidad o plenitud. Los personajes-objeto de El libro de los monstruos, incapaces de seguir con su vida cotidiana y sus funciones normales (aunque lo intentan), remarcan lo que Jean Luc-Nancy identifica como el "desobramiento" de la comunidad; la imposibilidad de la realización de la comunidad por su obra, producción o consumación:

Por eso la comunidad no puede depender del dominio de la obra. La comunidad como obra supondría que el ser común, como tal, sea objetivable y producible (en lugares, personas, edificios, discursos, instituciones, símbolos: en una palabra, en sujetos.) ... La comunidad tiene lugar necesariamente en lo que Blanchot denominó desobramiento. (67)

No se trata entonces, para Nancy, "de hacer, ni de producir, ni de instalar una comunidad" (67). De la misma manera, el pensador italiano Roberto Esposito explora la perspectiva improductiva de la comunidad, es decir, su falta constitutiva: Todos los relatos sobre el delito fundacional - crimen colectivo, asesinato ritual, sacrificio victimal - que acompañan como un oscuro contrapunto la historia de la civilización, no hacen otra cosa que citar de manera metafórica el delinquere — en el sentido técnico de "faltar", "carecer" - que nos mantiene juntos. (Communitas 34)

Tanto Esposito como Nancy identifican el mito de la comunidad, o la comunidad como mito; pero además, el mito como lo que es común a los miembros de la comunidad. En este sentido no puede haber una esencia, una inmanencia de la comunidad (o la comunidad como inmanencia), ya que no hay un ser común, objetivable y producible, sino que esta tiene lugar en el "desobramiento"; que es siempre y activamente "inacabada" y solo tiene en "común" un mito. Cabe entonces preguntarse por la posibilidad de su interrupción, en otras palabras: ¿puede la anti-representación de la comunidad funcionar como interrupción del discurso del mito comunitario? ¿Qué lecturas éticas son posibles ante la "absurdización" de la dicotomía nosotros-ellos que caracteriza lo político? ¿En qué 
clave política se puede leer la parodia de la retórica peronista que circula en estos textos? ¿Cómo interpretar la insistencia en los afectos y experiencias negativas como resultados de la vida en comunidad?

La figura de la metamorfosis remarca esa falta de la que habla el pensador italiano: el otro, sujeto-objeto de la transformación, representa no solo el cambio individual sino que, desde mi punto de vista, personifica un giro o distancia que es a la vez político y literario. Los "monstruos" operan como mecanismos dobles: por un lado son metacomentarios sobre la escritura (ponen en duda su verosimilitud, exponen su artificialidad), y por otro cuestionan e interrumpen la noción de comunidad como producto de la política (las instituciones, las prácticas) y lo político (el antagonismo amigo-enemigo).

La metamorfosis involucra un desbalance entre forma y contenido; se ubica en un espacio utópico en donde lo que no se corresponde puede coexistir. Este desfase entre significante y significado abre la posibilidad de una función crítica de la escritura: una distancia irónica similar a la técnica de la desfamiliarización u ostranenie que los formalistas rusos identificaron como una manera de des-automatización de la percepción propia del arte. Muchas veces no se sabe bien en qué se han transformado los "monstruos" de Wilcock, pero lo que sí queda claro es lo que no son; en el relato "Ilio Colio", por ejemplo, el personaje del mismo nombre se encuentra enormemente impedido en el ejercicio de sus funciones de asistente social porque de las tetillas le sale una especie de aceite espeso, como de máquina, que normalmente le corre hasta los pies, y eso lo vuelve muy escurridizo, además de ser una fuente inagotable de manchas grasientas. (Wilcock 74)

Ilio escucha desde la planta baja de un edificio "los alaridos de las víctimas indefensas aplastadas por la aplanadora de una vida demasiado compleja para sus modestos intelectos" (75), pero nunca consigue su objetivo de ayudarlos, ya que vive resbalándose en su propio aceite: "tendido en el piso en medio del charco de aceite de sus inagotables tetillas, busca en vano abrirse paso con ligeras contracciones del abdomen, como los gusanos: ‘YYa voy, ya voy!' se lo oye gritar, y cuando por fin llega a la escalera, resbala los primeros peldaños y cae hacia atrás" (75). El extrañamiento inicial que produce el desborde de aceite del cuerpo de Ilio se completa en su "metamorfosis" a la condición de gusano, que sin embargo no le impide continuar con la tarea imposible de asistir al prójimo.

La metamorfosis implica una experiencia de distanciamiento que se da al mismo tiempo en el sujeto transformado y en su entorno familiar y social. El personaje Mano Laso, por ejemplo, (en el relato del mismo nombre) es un estudiante 
de tercer año de arquitectura que "despertó una hermosa mañana cubierto de plumas blancas, saltó de la cama y fue a mirarse al espejo: tal vez esperaba ver una gallina o algo peor pero sus temores fueron infundados: seguía siendo un lindo muchacho, o lo que su madre solía llamar lindo muchacho" (11). Como en los talones le crecieron espolones duros, Mano Laso decide dedicarse a la arqueología y su hallazgo más notorio es un Fiat modelo 1949 sepultado con un insólito grupo de individuos sin cabeza ni manos, cincuenta mujeres jóvenes, un cacique y numerosas puntas de flecha. En general, los monstruos de Wilcock una vez transformados continúan (o intentan continuar) con sus actividades o profesiones habituales, o encuentran una más adecuada a su nueva forma. Poco cambia aparentemente en sus rutinas o en las de los seres que los rodean. Sin embargo, lo que se pone de relieve en estas transformaciones es lo absurdo de las actividades mismas, que pueden continuarse sin importar si el involucrado tiene forma humana o es un engendro de formas imprecisas. Esta ironía con respecto a los personajes transformados sugiere una diferencia en relación a las metamorfosis kafkianas: Gregorio Samsa pasa el resto de sus días recluido en su habitación, separado de su familia y de su actividad productiva de viajante de comercio, que queda suspendida indefinidamente por su nueva forma de insecto. Si bien su metamorfosis pone en cuestionamiento la dinámica familiar y social de su entorno, finalmente su aislamiento y su muerte preservan el sistema mismo que cuestionan. Los monstruos de Wilcock, en cambio, interrumpen y suspenden la lógica del sistema, que se muestra absurdo e inútil. ${ }^{3}$

Como Gregorio Samsa, los engendros de Wilcock conservan pensamientos y sentimientos humanos: sus transformaciones revelan siempre una falla o un vacío que se expresa en la relación con sus semejantes, y más precisamente en la inutilidad de estos sentimientos, como los del señor Zulemo Moss, que terminó convertido en un cenicero de madera y que es el cenicero más malvado de Italia, aunque "su única ambición es hacer daño a los demás y la perspectiva de hacerlo, nula, porque carece de medios" (13). Mesto Corpio se volvió tan chato que parece una hoja de papel. Colecciona mariposas, tal vez, dice el narrador, porque conservan una analogía con su persona, aunque "[e]sa delgadez que en las mariposas es una virtud consagrada a explicar y difundir los más logrados

Las metamorfosis de los personajes no apuntan a la "animalización" o "deshumanización" de estos sino, más bien, como lo nota Alejandra Laera en su artículo sobre Sergio Chejfec: "No hay acá deshumanización, en el sentido de lo humano enfrentado a lo animal, ni comparación (lo humano que parece animal: el humano como animal), sino liberación de lo animal de/en cada hombre" (105-117). 
dibujos de la mano de la naturaleza, en Mesto es lo contrario de una virtud, ya que está destinada a poner en evidencia, como sobre el papel, la forma absurda de ese monstruo soberanamente estrafalario que es el hombre" (63).

Mesto tiene ojos, nariz y boca, pero esos rasgos no son suficientes para determinar su humanidad, ya que es la estupidez, y sus cualidades negativas más notorias, las que son propias de lo humano:

los mismos elementos forman algo tan repugnante y anómalo que parece servir solamente para mostrar, y con cuánta crudeza, aquellas características de las cuales todos los mamíferos ... están afortunadamente exentos: la estupidez, la maldad, la codicia, en suma, las cualidades humanas más notorias. (64)

Son precisamente estas cualidades las que se ponen en evidencia en el papel, o sea en la escritura; en la superficie del cuerpo transformado se concentra la tensión entre el mundo exterior y el sentimiento interior de soledad. La transformación vuelve visible lo que estaba oculto y, al mismo tiempo, produce una ruptura en el orden de las cosas: como en el poema "El cuervo" de Edgar Alan Poe, o en el ensayo de Freud sobre lo siniestro, es lo unncany, lo familiar vuelto extraño que muestra lo imposible de la vida en comunidad, y es su naturaleza misma lo que aparece como siniestro. De tal manera, el viaje en los relatos de Wilcock opera como fractura del orden cotidiano y desfamiliarización del mundo: viaje y metamorfosis pueden leerse, entonces, como dos categorías críticas que cuestionan la idea de comunidad. Como lo nota Georges Van Den Abbeele: "Indeed to call an existing order (whether epistemological, aesthetic or political) into question by placing oneself 'outside' that order, by taking a critical distance from it, is implicitly to invoke the metaphor of thought as travel" (Introducción xiii).

En "La noche de Aix", un hermoso relato incluido en el libro El caos (publicado en español en el año 1974), el argentino Guido Falcone, que vive en París, decide pasar el fin de semana en Aix-en-Provence. Falcone "es un extranjero que todavía no domina a fondo las costumbres del país". El turista sale a recorrer la ciudad después de alquilar un cuarto en una pensión. Entra a un cine en donde pasan un documental sobre África y una vieja película argentina:

Los animales de África eran más o menos siempre los mismos... Después de un intervalo ... a aparecieron en la pantalla rectangular las estólidas caras porteñas que en su infancia le habían sido familiares, conversando en francés en un Barrio Norte poblado de almaceneros retirados y prostitutas en actividad. Fragmentos de la Diagonal, una entrada a un subterráneo, una calle de paraísos, hasta lo cierto le resultaba falso, como en un cuadro académico. (134) 
A su vuelta, Falcone encuentra la pensión cerrada y tiene que pasar la noche a la intemperie. Camina por la ciudad buscando un lugar en donde dormir. Se acuesta entre las plantas de un terreno baldío y allí, bajo el cielo estrellado, siente la distancia que lo separa, no solo de su país natal, desfamiliarizado en la vieja película argentina por la superposición y confusión de tiempo-lugar e idioma, sino también de la historia de la humanidad:

en el silencio sin ladridos de perros, un argentino se acurrucaba entre tejidos de lana de oveja como los primeros pobladores de Francia que tal vez eran negros, y a pesar de una preparación literaria de muchos años, o quizás gracias a ella, conseguía percibir la intensidad de la pureza nocturna que pudo haber exaltado cualquier instante de la vigilia del hombre magdaleniano cuando, exiliado de su cueva familiar por haber infringido el rito religioso, erraba por el valle del Ródano ... durmiendo bajo los árboles como Falcone. (138)

El hombre magdaleniano, como Falcone, como el mismo Wilcock, y como su colección de monstruos que han sufrido metamorfosis varias, se ha auto-exiliado de la vida en comunidad en el retiro de la soledad extrema. La experiencia de la soledad profunda es análoga a la de la metamorfosis y el viaje: como el único Robinson en una isla desierta, Falcone desanda la historia y retorna al estado idílico de los primeros hombres del planeta; el estado pre-político que, a su vuelta a la civilización, después de la noche a la intemperie en la cual se da cuenta de que ni siquiera el lenguaje puede comunicar su vivencia, lo transforma en un "verdadero viajero": un turista de la historia. Esta distancia crítica será condición fundamental de la escritura de Wilcock, la cual se manifiesta insistentemente en sus relatos como resultado de la imposibilidad de la comunidad como lugar de pertenencia:

Al mismo tiempo, aislado por el frío casi poliédrico ... sentía como un símbolo más de la noche la ausencia absoluta de cualquier deseo de expresar su soledad vertiginosa, de encarnarla en un esquema comunicativo cualquiera que no fuera un título sin más destinatario que el gusto de la evocación, por ejemplo "La noche que dormí en un baldío de Aix." O "La noche de Aix". Y esa certeza suya de que nadie en el futuro comprendería su experiencia . . . constituía la confirmación de la esencia misma de la experiencia, que era la soledad. (138)

En la experiencia del viajero, la soledad opera como transformación interior y suspensión del mundo: este sentimiento define también las metamorfosis corporales de los monstruos de Wilcock que, como turistas, practican la observación implacablemente irónica de la historia y del mundo que los rodea, pero fundamentalmente, de las relaciones afectivas con ese ámbito ajeno que es la política. 
De manera estructural, estos personajes se asemejan a lo que Ana María Amar Sánchez identifica como la figura del "perdedor" en la literatura, conformada por personajes que resisten, que no se "adaptan" a las reglas de la vida en comunidad y que representan metáforas de conflictos políticos y éticos (Amar Sánchez).

Si bien la idea del turista tiene connotaciones de tipo económico - el consumo de bienes y experiencias culturales en una sociedad capitalista-, la metamorfosis y el viaje sin embargo involucran prácticas de desplazamientos y experiencias similares a las de un turista en tierra extrajera; crean un alejamiento tanto espacial como simbólico que encubre cierta nostalgia utópica que aparece velada, como un fantasma: en las imágenes de la Argentina superpuestas al francés en el cine de Aix; en la plaza bombardeada (por un dictador que se llamaba conejo) ${ }^{4}$ que sueña Falcone en el terreno baldío; en Colquetá, el pueblo carnavalesco y peronista del cuento "Felicidad"; en la casa de la calle Solís donde los enanos torturan al sobrino provinciano; en el país imaginario de la despótica Casandra, y en tantos otros "monstruos" que interrumpen la vida en comunidad.

Svetana Boym declara que la nostalgia es una emoción histórica que está relacionada, más que con un desplazamiento en el espacio, con un cambio en la concepción del tiempo (7). Sin embargo, los solitarios de Wilcock no experimentan la nostalgia como un sentimiento que proponga restaurar un pasado perdido en la esperanza del futuro, sino que a través de sus cambios radicales marcan la falta; muestran la imposibilidad misma de la nostalgia, ya que no puede haber nostalgia verdadera si no hay "Patria verdadera".

Ricardo Herrera identifica el cambio en la escritura de Wilcock de los 40 (poesía neorromántica de "regresión órfica" y "restauración formal") con respecto a un centro en su vida y su obra que "atrae y repele": el peronismo. El lirismo modifica a la ironía; lo sublime se transforma en grotesco (Herrera). El cambio se produce también en la percepción de lo político a través de la experiencia de la nostalgia imposible; como señala Herrera, ya no es viable para Wilcock el deseo por un universo poético órfico que acarree una mitología sentimental, formal e ideológica; de la misma manera, propongo, ya no es posible la nostalgia del retorno a la patria cosmopolita, fundada en el antagonismo civilización o barbarie. ¿Por qué no pensar entonces que la distancia irónica practicada en su narrativa facilitó una reevaluación del fenómeno del peronismo en su escritura? ¿Por qué no pensar que esta transformación que se dio en los años sesenta y setenta (Wilcock falleció

4 En alusión al bombardeo de Plaza de Mayo en Junio de 1955, que resultó en un fallido intento de golpe de estado contra el presidente Juan Domingo Perón. En septiembre de ese mismo año las fuerzas armadas derrocaron a Perón en lo que se llamó la "Revolución Libertadora". 
en 1978), en los cuales continuó escribiendo y publicando en español y en italiano, produjo también un cambio en su percepción de lo político?

En Política y soledad Marcos Santucho y Verónica Galgione se preguntan: ¿Cómo sería concebible la soledad en ese espacio común que constituye la política? ¿Será la soledad acaso una rareza, una anomalía, una falla en la política? (9). Desde esta perspectiva, la soledad cuestiona la posibilidad de lo colectivo e instala las problemáticas de la construcción de la comunidad y los lazos afectivos y productivos que la constituyen. Como hemos notado, tanto Nancy como Esposito remarcan el carácter de mito de la comunidad; un mito que la imagina como utopía pero, además, pensando en la definición de la soberanía y lo político de Carl Schmitt, como comunidad de "amigos" que se constituye en la diferencia radical y en la guerra. La soledad entonces podría ser lo que es propio del enemigo. O, por el contrario, como plantea Jacques Derrida, sería lo propio del soberano y la soberanía: "This absolute political sovereignty, 'Adam sovereign of the world like Robinson of his island,' this absolute sovereignty of man over the entire world, i.e. a sovereignty without obstacle and therefore without enemy - and therefore, Schmitt would say, without politics -" (The Beast and The Sovereign 47). Robinson en su isla: una isla que funciona como el espacio privilegiado para la suspensión de lo político por la experiencia de la soledad profunda. Propongo entonces pensar la soledad como experiencia que interrumpe lo político.

En estos relatos la soledad se representa contra la experiencia de lo común y por momentos se parece a lo que Siane Ngai denomina "stuplimity", una mezcla de la estupidez y lo sublime. La soledad, la idiotez y la imposibilidad de la comunidad constituyen una "isla de la desesperación", como llama Robinson Crusoe a la isla de su naufragio; un estado en el cual, a través de la mirada del humor negro, estos afectos y estados negativos indagan en la naturaleza antagónica de lo político y la encuentran absolutamente estúpida.

Wilcock crea su propia distopía insular en El estereoscopio de los solitarios (1998), pero en este caso el destino de los personajes no siempre es producto de la fatalidad sino de la voluntad. El relato "La isla", por ejemplo, presenta un falso Robinson o falso Quijote, ya que el personaje, Grombio, "[i]mpulsado por la lectura de la novela Robinson Crusoe" decide transformar su departamento en una isla desierta (80). Grombio intenta entonces crear una ficción a partir de una ficción, y en este mismo gesto la pone en duda, la problematiza. Porque Grombio no navega en el mar del infortunio, ni habita la isla de la desesperación, sino más bien la de la ironía y la parodia. Al parodiar a Robinson, Grombio devela el carácter ficcional del mito del sujeto soberano, e ironiza además la nostalgia por 
ese mito. La mujer de Grombio, Crabua, que también había leído la historia de Robinson, es consciente del simulacro nostálgico de su esposo:

fue a buscar la novela y le hizo ver al marido que en realidad Robinson disponía de una cantidad de muebles y objetos salvados del naufragio, un tintero, armas, quesos, rollos de láminas de plomo, hamacas, limas, un armario, en fin, más cosas de las que ellos poseían en pleno barrio residencial. (80)

Pero no hay caso: el marido decide desprenderse de todas sus posesiones y comenzar el aislamiento. Crabua llora, se aferra a los objetos, se desmaya, por momentos pierde la razón, hasta que por fin se resigna: "A pesar de eso, algo consiguió salvar, pero no la estima de sus vecinas, lo que más que cualquier consideración sobre las islas la indujo a no salir nunca más de su casa, por lo menos de día" (81). La esposa cambia su nombre a Viernes, y hace lo que puede para mantener los trajes de Grombio limpios para que siga yendo a trabajar al banco. Viven felices de lo que el marido encuentra en la basura y trae a la casa en sus excursiones por el barrio. Grombio y Crabua escuchan amorosamente el silencio de la noche, "[i]nterrumpido solamente por los gritos helados de los televisores" (83), índices de que el experimento y la experiencia misma de la soledad es posible como una isla dentro de una isla, aunque no como estado pre-político absoluto, sino más bien como extrañamiento de la política y lo político.

Los textos que nos ocupan no narran la nostalgia por un origen fallido; el deseo utópico de un nuevo comienzo en el cual el soberano absoluto ejerce su voluntad sobre las cosas. Las "islas" de Wilcock son islas dentro de la comunidad como isla; las soledades improductivas que representan las metamorfosis y el viaje son posibles porque se dan en la comunidad, como una isla dentro de una isla; como metacomentario y como estrategia de resistencia a su mitologización.

De la misma manera, en el cuento "Hundimiento", del volumen El caos, Ulf Martin naufraga en una isla que se está hundiendo. La tragedia de Ulf se debe a que asesina al amante de su novia, sin pensar primero que este era el único que sabía manejar el barco. Podríamos decir entonces que Ulf naufraga en la isla de su propia estupidez; no puede salvar nada de la embarcación, pero cuando explora la isla encuentra una casucha con objetos en su interior, por ejemplo un recibo por la compra de un salvavidas, que obviamente no le servirá para nada. Ulf, a diferencia de Robinson, ha demostrado ser una persona que fracasa en todo, pero la vida en las grandes ciudades está organizada de tal modo que hasta al ser más inútil le basta ser simpático o tener familia para subsistir durante años sin mayores inconvenientes porque las consecuencias de su inutilidad se compensan, anulándose, con las de los demás (128). 
El hundimiento de la isla es también, para Ulf (y como se verá más adelante, para los idiotas del doctor Attendu), el de sus "pretensiones y convenciones"; ya no le queda nada, dice el narrador, ya ni siquiera se llama Ulf Martin. Ulf se hunde, y en esa certeza del fin, sentencia el narrador: "si ha sido un hombre, lo ha sido solamente un instante antes de su muerte" (130): como Mör en su nave perdida en el espacio, Ulf descubre la revelación en el momento de soledad profunda, cercano a la muerte y lejano al mundo. Es entonces, ese instante en el que ya no hay ni siquiera nombre propio, el momento puro de la soledad en el que todo se pone en suspenso - los afectos, los otros, la sociedad-: la comunidad desaparece y con ella su utopía, la posibilidad de su mito.

Propongo leer entonces a Grombio parodiando a Robinson; a Ulf en la isla que se hunde en el mar; a Mör en una nave espacial en forma de sandía en órbita parabólica para siempre en el espacio; a Falcone en un terreno baldío en la noche helada de Aix; a Illio Colio como un gusano que resbala en su propio aceite, y a tantos otros solitarios y monstruos o idiotas idílicos en su isla metafórica suspendida, aislada, en medio del mar de la historia como gestos histriónicos: tableaus que ponen en escena a la política y lo político como pura estupidez.

\section{Estúpidos ángeles}

La estupidez funciona como paradigma distópico y mirada desfamiliarizadora, en la cual la construcción de una "comunidad imaginada" (Benedict Anderson) o "imaginaria" (Phillip Wegner) pierde su valor como horizonte social. La narración utópica, señala Wegner, crea comunidades imaginadas al mismo tiempo que cumple la función de cuestionar la estabilidad ideológica de la realidad presente (23). Por eso mismo, la utopía encarna una crítica del presente y una promesa a futuro; la condición misma de su existencia es paradójica, ya que su naturaleza es que permanezca siempre incompleta, como promesa, que una vez cumplida, pierde precisamente su calidad de utópica. Como producto de la modernidad, la narración utópica es definida por Theodor Adorno como el imaginario de la transformación social total: "Whatever utopia is, whatever can be imagined as utopia, this is the transformation of the totality" (citado en Bloch 3). Ernest Bloch identifica este deseo de transformación del mundo como la mayor posibilidad de felicidad social (4). Utopía y distopía están, muchas veces, simbiotizadas, puesto que en la invención de un nuevo orden posible se inscribe la crítica del orden presente. Bloch traza una analogía entre el espacio imaginado de la utopía y la figura de la quimera como collage: la utopía es también un no-lugar que se forma de partes y representaciones ya existentes, de la misma manera que los monstruos de Wilcock son un collage 
de las peores y más absurdas cualidades humanas y de las imposibilidades de la vida en comunidad.

El relato "Alfred Attendu" de La sinagoga de los iconoclastas, lleva la idea de la comunidad utópica hasta el absurdo. El Dr. Attendu dirige un "Sanatorio de reeducación" en el periodo que va de 1940 a 1944 que, afirma el narrador, "fueron sus años de oro". La referencia al contexto histórico del nazismo debe leerse como una operación paradigmática que contrasta y compara lo político y la estupidez. La idiotez, el embrutecimiento de la razón y, por sobre todo, la imposibilidad de ponerse en el lugar del otro, y del diálogo con uno mismo (como lo postula Hannah Arendt con respecto a la banalidad del mal), están siempre relacionados con un sistema político, social, cultural o, incluso, son la parodia de una teoría social, económica, teológica o política.

La tesis de Attendu, que consiste en que "[d] urante siglos, la opinión habitual ha considerado que la idiotez es un síntoma de degeneración del hombre; el doctor le da vuelta al prejuicio secular y afirma que el idiota es el prototipo humano primitivo del cual sólo somos la versión corrompida" (82), propone un edén poblado de imbéciles a los cuales llama "les enfants du bon Dieu". Después de todo, afirma el narrador, las razones de su teoría son más que evidentes: "Desde lo alto del Haut-les Aigües había visto ... los ejércitos de uno y otro bando ir y venir, como en un film cómico, . . . construyendo para destruir, arrancándose banderas de modesto precio al precio de la vida. Sus enloquecidas confusiones superaban la comprensión humana" (83).

Attendu comprende que la idiotez perfecta es la condición ideal y su objetivo es descubrir los medios para reducir a sus pacientes a un estado de retraso mental angélico. El primer paso es abolir cualquier relación de estos con el lenguaje, y el paso siguiente suprimir cualquier traza de "buenos modales, limpieza, orden y similares características subhumanas adquiridas precedentemente" (84). La distopía de una anti-comunidad de idiotas contrasta con el periodo histórico más nefasto de la historia de la humanidad: la Segunda Guerra Mundial, en el que se derriban muchos de los valores de la modernidad, y sobre todo, la idea de progreso y racionalidad históricas. El extrañamiento y la distancia irónica de esta distopía opera de la misma manera que las metamorfosis o los viajes; pone entre paréntesis la posibilidad misma de la vida en comunidad y los presupuestos histórico-políticos que la fundamentan. La ideología nazi de un pueblo de raza superior es tan distópica como la anti-comunidad de idiotas angélicos de Attendu. La diferencia más significativa es que en esta anti-comunidad se eliminan las ideas del enemigo, la guerra y la violencia. Incluso si en este relato la ironía enmarca un fragmento de la historia, esta aproximación a lo real produce 
el extrañamiento necesario que vuelve absurdos lo político y la política como fundamentos de la historia en cuanto locus utópico. La distancia irónica es una herramienta hermenéutica que pone en evidencia el discurso político de la comunidad como significante vacío, ya que ambos casos - tanto el proyecto de una nación de individuos superiores como la noción de una comunidad de retrasados mentales como seres perfectos - sugieren por igual la plenitud de la comunidad ausente como ficción política del lenguaje. ${ }^{5}$

La teoría del Dr. Attendu se funda en la metamorfosis o transformación de sus pacientes y en la eliminación paulatina de toda relación racional o afectiva con el prójimo. La supresión de la racionalidad es una condición primordial para la desmitificación paródica de la comunidad como plenitud, propia del discurso político que, como señala Ernesto Laclau, construye un "nosotros inclusivo". La exageración irónica de Wilcock hace pensar en la idea de la "banalidad del mal" tal como la define Hannah Arendt, refiriéndose a la burocracia del aparato de exterminación nazi. ${ }^{6}$ Arendt remarca que la incapacidad de pensar es fundamentalmente la incapacidad de ponerse en el lugar del otro; es decir, de construir y conservar un vínculo solidario. Para ponerse en el lugar del otro es necesario algún tipo de "imaginación comunitaria" o de identificación con el prójimo que resulta de la racionalidad. Luis Avilés sostiene que la idea del "dos en uno" de Arendt, la capacidad de diálogo conmigo mismo, "es el punto importante que liga a la consciencia con lo ético y lo político" (22). Más adelante, remarca que la falta de pensamiento se asemeja a un estado de sonambulismo: "Vivir sin rumbo, caminar dormido, ser un sonámbulo o quizás un zombi" (24). La anti-comunidad de idiotas del Dr. Attendu presenta la paradoja de que este estado de estupidez

5 Me refiero a la idea de plenitud que maneja Laclau en La razón populista: "la identidad popular expresa/constituye - a través de demandas insatisfechas- la plenitud de la comunidad que es negada, y como tal, permanece inalcanzable; una plenitud vacía, si se quiere" (137).

6 Véase Eichmann in ferusalem. Arendt nota la absurda inhabilidad de Eichmann con el lenguaje y su incapacidad de comunicación: "The German text of the taped police examination, ... constitutes a veritable gold mine for a psychologist - provided he is wise enough to understand that the horrible can be not only ludicrous but funny. Some of the comedy can not be conveyed in English, because it lies in Eichmann's heroic fight with German language, which invariably defeats him". Más adelante Arendt escribe que "he was genuinely incapable of uttering a single sentence that was not a clichê" (48). Esta incapacidad está íntimamente ligada a la imposibilidad de pensar: "The longer one listened to him, the more obvious it became that his inability to speak was closely connected with an inability to think, namely, to think from the standpoint of someone else" (49). Es interesante que Arendt considere que la transcripción de la declaración de Eichmann puede ser leída como ficción, y más aun, como ficción irónica, de manera que las similitudes con los idiotas del Dr. Attendu son evidentes. 
(podríamos decir "Estado", en el sentido de organización política en este caso a todas luces "deficiente") invierte y parodia la ecuación de Arendt, sugiriendo que la verdadera idiotez humana, aquella que carece de dimensión ética, no está solamente en la falta de pensamiento, sino en el pensamiento de lo político en sí (es decir, en el antagonismo bélico).

En su conocido estudio sobre los fundamentos discursivos del peronismo, Sigal y Verón señalan como elementos retóricos principales al antagonismo patriaantipatria y a la identificación de Perón con el trabajador. La retórica peronista se basa en el trabajo y el trabajador como figuras claves para comprender cierto universo simbólico fundado en una lógica nosotros-ellos: "Ningún Peronista debe sentirse más de lo que es, ni menos de lo que debe ser. Cuando un Peronista comienza a sentirse más de lo que es, empieza a convertirse en oligarca", afirma Perón en una de las Veinte Verdades peronistas (Verdad $\mathrm{N}^{\circ}$ 7). Ser oligarca es, entonces, una condición que nace del pensamiento, o una manera de "sentir" que no se corresponde con la del trabajador. El trabajo constituye una condición ontológica del sujeto, ya que para el justicialismo solo puede existir una sola clase de hombres. Es precisamente el pensamiento lo que puede transformar al trabajador en oligarca, cuando el trabajador se cree "más de lo que es" (pero no menos). En otras palabras: el peronista "de bien" es el que cumple las verdades peronistas, sin pensar que es más de lo que es, porque "[p]ara un Peronista de bien, no puede haber nada mejor que otro Peronista" (Verdad No 6). El cuento "Felicidad" de El caos ironiza esta Verdad y la relación entre (falta de) pensamiento e identidad peronista, postulada en la Verdad número 7.

En el pueblo de Valdivieso, el Secretario del Partido Oposición Constructiva le pide a Trenti, Prosecretario Honorario, que vaya al pueblo de Colquetá para el último día del carnaval porque, como lo ha prometido el Comisionado Interventor del Partido Peronista, se quemará a un opositor: "Para expresar simbólicamente el ideal del Consejo Superior Unánime del Partido, que es como todos sabemos eliminar la Oposición" (97). Trenti no quiere ir, sobre todo porque ya no queda nadie de la oposición, pero el Secretario le responde: "—Quedamos nosotros, los Constructivos. Aunque votamos por Perón, el Consejo Superior ha decidido hace dos semanas declararnos Oposición; ayer llegó el telegrama" (97). Trenti debe ir a Colquetá a rescatar a Madama Souza, famosa oradora de barricadas; la única Opositora Constructiva que ha quedado en el pueblo porque los demás se han escapado. Ya en el pueblo entra en la comisaría y, después de declarar sus intenciones, lo meten en un calabozo. El Comisario amenaza: "Vea amigo, no le permitiremos que siga rondando impunemente las comisarías. Sepa que en este país se acabó con la política, para siempre" (101). Trenti encuentra a 
Madama Souza en el calabozo pero, aunque él debe quedarse allí, a ella la dejan en libertad. En la comisaría aparecen policías disfrazados de piratas y el Comisionado Interventor del Partido Peronista disfrazado de noble inglés le pregunta cuál es su último deseo. Ante la desesperación de Trenti, el Comisionado declara: Nada de sentimentalismos, por favor, después de todo, si ha accedido a colaborar con nosotros en una de las páginas de la historia más hermosas, más fervorosas de la Provincia, no es el momento de personalizar sentimientos tan universales como el patriotismo... Frente a la majestad de una Nación, ¿qué es, qué vale la masa anónima que la compone? Cero, ni más ni menos que cero. (105)

A Trenti le duele la muela y lo llevan a la enfermería. Un ayudante vestido de marajá hindú le aplica una inyección. Acto seguido empieza a sentirse confundido, y desde su nebulosa felicidad, observa los diferentes funcionarios disfrazados que lo suben a un camión adornado para iniciar el desfile por el pueblo que le lanza serpentinas, flores y papel picado. En medio del clima festivo general que se describe con un tono de pintoresquismo sarcástico, la enfermera que conduce el camión grita, de vez en cuando, “como un trueno: ¡Viva Perón!” (109). El carnaval, los disfraces, el pueblo reunido cantando "entrelazando las manos con inocente fervor "Los muchachos peronistas", la plaza y en general todo el clima del relato es una sátira cómica y absurda de la mitología y la simbología del peronismo. Trenti observa todo desde su estado narcótico de "apatía muscular" (111), con una evidente incapacidad de pensar. Los funcionarios y el pueblo disfrazados forman un séquito bajo la lluvia que arrastra papeles descoloridos y arruina disfraces. La narración tiene un tono inocentemente cómico, que los comentarios de los personajes disfrazados acentúan. Finalmente Trenti es trasladado a una pira en medio de la Plaza en donde pronuncia un discurso inconcluso:

-Querido público ... agradezco conmovido esta manifestación de afecto a mi entender inmerecida, y antes de rematar la fiesta quisiera confesarles que éste ha sido el día más feliz de mi vida, y que nunca sentí como en este momento el lazo indisoluble que me une a mis conciudadanos, ya sea de mi pueblo o de cualquier otro pueblo o ciudad de esta vasta tierra bendita y bienamada que me dio el ser. (114) 
Rápidamente lo rocían con nafta y le prenden fuego, en una "hoguera patriótica" ante la ovación de la multitud. ${ }^{7}$ Obviamente el relato da un panorama de todos los mitos y estereotipos peronistas y una primera lectura política lo interpretaría como parodia histórica del movimiento y su burocratización partidaria. Si bien esta es una lectura innegable, me interesa dejarla de lado para explorar especialmente la relación que este relato postula entre estupidez y peronismo, y en un sentido más amplio entre estupidez y política.

"Felicidad" postula lo político como simulacro y la política como estupidez. La necesidad del enemigo, expresada en las nuevas ramas de la "Oposición" interna creadas por el partido mismo que ya no encuentra oposición, porque "se acabó con la política para siempre", reproduce la irracionalidad de un mecanismo que traduce el disenso en exterminio. Parodia la arbitrariedad de este mecanismo, en el cual el enemigo es una figura móvil y ambigua, siempre a disposición para legitimar la soberanía del Estado. De la misma manera la política no se basa en el pensamiento o la convicción sino en una serie de gestos vacíos, encarnados también en los "cargos" o "títulos" políticos de los personajes que simulan el aparato burocrático del partido, representado como un sistema de nombres intercambiables que pretenden ser algo que no son, como los disfrazados del carnaval. ${ }^{8}$ Como el trabajo mecanizado, la mecanización de la política es también alienante y en ese caso es el aparato del Estado el que representa una máquina productora de estupidez. En "Felicidad", el peronismo encarna un manera de hacer política como estupidez; y más aun: la estupidez como estado colectivo, resultado de la política, y también como límite de la política. La condición narcotizada de Trenti le impide pensar, y sin embargo es capaz de pronunciar un discurso con todos los clichés políticos que, exacerbados por la situación, pierden sentido y se vuelven un teatro de la política y de lo político como máquina de producir antagonismos.

No es el pensamiento sino el trabajo la condición ontológica peronista tanto de la comunidad como del individuo. La cuarta de las "Veinte verdades peronistas" proclama: "No existe para el Peronismo más que una sola clase de hombres:

7 Según la edición de Editorial Sudamericana, "Felicidad" fue publicado por primera vez en italiano en 1958 en Il Mondo; en Il caos lleva el título "Trenti re" (versión que cambia los nombres de Perón y Evita por López e Irrisita), pero luego, en Parsifal, Wilcock restituye el título original del cuento; es decir que el relato pasa por diferentes etapas de traducción y revisión que lo modifican.

8 En el relato "El caos" también se representa la idiotez y el simulacro de la política, en donde el soberano basa la política del Estado en las fiestas caóticas y el cambio de roles de los personajes. 
los que trabajan". ${ }^{9}$ El trabajo es un componente de la vida en sociedad que está completamente ausente de las islas y los idiotas de Wilcock. ¿Cómo interpretar, entonces, la relación existente entre idiotez y trabajo? Desde la noción de alienación de Marx, el trabajo mecánico y rutinario del sistema capitalista industrial es la fuente de la alienación que el Estado impone al trabajador, que tiene el efecto opiáceo de un arma en contra del proletariado (Ronell 57). Como señala Avital Ronell, para Marx "stupidity consists in the inability to perform dialectics ... in the historical materialist sense" (57). Desde esta perspectiva, la estupidez es lo que impide que se realice la revolución, o dicho de otro modo: la estupidez obstaculiza que se cumpla la utopía.

En la escritura de Wilcock la idiotez no solo anula la posibilidad dialéctica de la historia, sino la historia misma, como horizonte y concepto funcional para cualquier utopía política. En el relato "Carlo Olgiati" de La sinagoga de los iconoclastas (1972), el maestro del mismo nombre elabora su teoría "sociobiológico-económica" que es, según el narrador, "[u]na primera versión senil, cualquier cosa menos exhaustiva" (59) de su libro titulado La lucha de los grupos en la fauna y la flora que fue retirado de las librerías por su propio autor, ya que ningún medio le había dedicado una reseña periodística. La intrincada, irónica, disparatada y totalmente contradictoria teoría del Profesor Olgiati, ilustra y pone en escena el sinsentido de la historia, y en especial de toda teoría utópica o programa político. En una especie de parodia sarcástica del materialismo histórico, el "olgiatismo" se define como:

más simplemente metabolismo histórico, la teoría supone y demuestra precisamente la inevitabilidad del olgiatismo, entendido como estado ideal en que todos los grupos se funden en uno solo, de modo que los conceptos de Estado, ley, dinero, caza, sexo, policía, sueldo y transformación de energía, calor y trabajo mecánico dejan de tener la menor función, y por así decirlo, desaparecen de la historia. $(59)^{10}$

El "olgiatismo" se presenta como un estado ideal de estupidez, improductividad, e irracionalidad; una utopía cómica: "Último entre los grandes constructores de sistemas, Olgiati era también conocido como propietario de una fábrica de galletas" (58). En esta "minuciosa, compleja, e improbable teoría

9 Ver "Las veinte verdades peronistas", accesible en: http://www.galeon.com/doctrinaperonista/ album623155.html

10 El sentido común dictaría que en esta enumeración dijera "raza" en lugar de "caza"; una muestra más de que, para Wilcock, el sentido común es el más estúpido de los sentidos. 
génetico-económica", no se demuestra, obviamente, nada más que la idiotez histórica y la imposibilidad de predecirla más allá su irracionalidad:

Fundamentalmente, los oligiatistas creen que la historia - llamada también meteorología social - está gobernada por leyes bioquímicas que la mente humana (léase Olgiati) debería ser capaz de descubrir ... [.] Como sucede con frecuencia, hasta las dudas del maestro se convierten en dogma para los discípulos. (6o)

La degradación histórica está determinada, para el profesor, por diferentes factores llamados idealistas, "como el antagonismo deportivo, el sentido de la propiedad, el incesto extra-familiar y la prohibición de comer carne cruda" (61). Es decir, la estupidez produce una lógica política propia, que cuando se postula como teoría racional de la historia cae en el peligro de ser, como el sistema de Olgiati, un "auténtico laberinto de causas y efectos en el cual resultaría imposible cualquier predicción" (62).

En "Liberación", relato que forma parte de El estereoscopio de los solitarios, Sertén, "heredero de varias y cómodas fortunas, amante del deporte y la vida al aire libre" (30), decide, para liberarse de las ambiciones del hombre común, hacerse una lobotomía. Sertén "ha cambiado y se ha perfeccionado" y se ha sometido a múltiples operaciones del cerebro que le hicieron perder todo sentido de la orientación, "del deber, la vergüenza, la sugestión, el remordimiento, el miedo, la modestia, la piedad, el insomnio y otras anomalías similares" (32). ${ }^{11}$ Como los idiotas idílicos del sanatorio del Dr. Attendu, Sertén carece de la capacidad de razonamiento en la que se funda el vínculo social y toda concepción de la historia y de la comunidad. Así es como en el relato "Elvio Tatti", por ejemplo, el personaje del mismo nombre ha adquirido la forma toroidal; y aunque no presente signos de actividad mental sigue, sin embargo, respirando. Su característica más vital es que tiene un hedor repugnante. El narrador se pregunta, entonces, en dónde está el alma de Elvio; llega a la conclusión de que su alma es su hedor, y reflexiona: " ¿y no ocurrirá lo mismo con todos nosotros, puesto que, como él, todos estamos mantenidos con vida en terapia intensiva, hasta la inevitable muerte biológica?" (80). Es que en la escritura-isla de Wilcock la historia, como Elvio Tatti, no muestra ya signo de actividad mental; y cualquier imaginación

11 Este relato recuerda "Cirugía de extirpación" de Macedonio Fernández: aquí al personaje Cósimo Schmitz le extirpan "el sentido de futuridad" y solo le queda la percepción del futuro de ocho minutos. Como en "Liberación", la imposibilidad de pensar el futuro es también un estado apolítico. La semejanza con las vivencias de Mör del cuento de Wilcock "En el espacio" también son interesantes. 
utópica lleva inevitablemente al ridículo y la destrucción. Como afirma en el relato "Aaron Rosemblum":

Los utopistas no reparan en medios; con tal de hacer feliz al hombre están dispuestos a matarle, torturarle, incinerarle, exiliarle, esterilizarle, descuartizarle, lobotomizarle, electrocutarle, enviarle a la guerra, bombardearle, etcétera: depende del plan. Reconforta pensar que, incluso sin plan, los hombres están y siempre estarán dispuestos a matar, torturar, incinerar, exiliar, esterilizar, descuartizar, bombardear, etcétera. (La sinagoga de los iconoclastas 22)

La relación entre utopía y estupidez se da en el terreno de lo político, no solamente porque presenta un programa comunitario a futuro, sino porque este se realiza en una dimensión bélica (los utopistas vs. "el hombre"). Frederic Jameson subraya la utopía como concientización de los límites del entendimiento: "It suggests that at best Utopia can serve the negative purpose of making us more aware of our mental and ideological imprisonment ... and that therefore the best Utopias are those that fail the most comprehensively" (Archaeologies of the Future xii). Mostrar el límite del pensamiento político y utópico parece ser también el propósito de las distopías anti-comunitarias de Wilcock, no para proponer una nueva utopía, sino para mostrar su condición contradictoria, violenta e ilusoria.

\section{Viajeros extremos}

Una diferencia entre metamorfosis y viaje es que la primera no es un traslado de lugar sino de forma, es decir: condensa las características del viaje pero invertidas. No es el viajero en su desplazamiento el que produce, en el encuentro con el otro, el saber y el poder para su dominación, sino que el sujeto de la metamorfosis se presenta como el otro mismo, exponiendo su "otredad" a los demás; invirtiendo las categorías epistemológicas y volviendo extraña la propia cultura y la vida en comunidad. Frente al volcán que echa lodo, la mariposa, delgada como un papel; el asistente social al que le sale aceite por las tetillas; la masa informe de un hedor espantoso; el ser de forma toroidal, y toda la galería de metamorfosis de Wilcock, la sociedad, persiste en comportarse como si estas transformaciones no se hubieran producido (e incluso en muchos casos son las características absurdas de estos seres lo que los hace famosos o exitosos), volviendo evidente lo absurdo de las relaciones humanas y la sociedad en su totalidad. La metamorfosis, entonces, es la forma más transgresiva de viaje; el viaje permanente en el que todas las certezas pierden su valor. Al mismo tiempo, el viaje es también una forma de metamorfosis: un proceso de desprendimiento de los hábitos y de la cultura que forman parte de la vida en común; pero sobre todo, en la escritura de Wilcock el 
viaje es el proceso mismo de transformación sin retorno, que marca la experiencia de la soledad profunda y el distanciamiento definitivo del vínculo con los demás.

Mör, personaje del relato "En el espacio" de El estereoscopio de los solitarios, fue enviado como una broma por sus amigos del club en una nave hacia el espacio en órbita parabólica. Cuando Mör se da cuenta de que no volverá nunca a la tierra, empieza a componer un largo poema titulado "Impresiones de viaje", pero no tiene lápiz y no puede escribir. Como en "La noche de Aix", la intensificación de su soledad es directamente proporcional a la imposibilidad de la escritura, o sea de la comunicación de una experiencia o de la conexión con el mundo. Trata de memorizar el poema pero "cada veinte líneas que Mör agregaba se olvidaba de otras tantas" (67). El viaje es el medio para la metamorfosis del viajero y Mör comienza un proceso de introspección y de retrospección. Vuelve a la "tercera adolescencia": "El placer de masturbarse en ausencia de la gravedad llenaba sus noches de presencias graciosas y dúctiles... Dormía mucho, y cada mañana cuando se despertaba, creía que se despertaba en un mundo nuevo" (66). En el aislamiento de su nave vuelve al estado casi fetal, flotando en la soledad de la noche, "enteramente ocupada en visiones a ojos cerrados, en una especie de cine personal, a veces erótico y a veces documental" (67). ${ }^{12}$ Pasa quince años solo en la nave y todavía le quedan más de veinte. Pero:

No llegará, piensa, cuando piensa... sobre todo porque no tiene ganas... Desde la partida le fue aclarado que su órbita era parabólica, o sea, que no llegaría a ningún lugar. El viaje es todo, y la repetición; pero Mör se da cuenta ahora de que hasta la repetición comienza a palidecer, a babear, a marchitarse, como un texto impreso demasiadas veces. (67)

12 Como he mencionado anteriormente, este relato tiene semejanzas con "Cirugía de extirpación" de Macedonio Fernández, en el cual a Cósimo Schmitz le han extirpado el sentido de la futuridad: "El futuro no vive, no existe para Cósimo Schmitz, el herrero, no le da alegría ni temor. El pasado, ausente el futuro, también palidece, porque la memoria apenas sirve; pero qué intenso, total, eterno el presente, no distraído en visiones ni imágenes de lo que ha de venir, ni en el pensamiento de que en seguida todo habrá pasado. Vivacidad, colorido, fuerza, delicia, exaltación de cada segundo de un presente en que está excluida toda mezcla así de recuerdos como de previsión; presente deslumbrador cuyos minutos valen por horas. En verdad no hay humano, salvo en los primeros meses de la infancia, que tenga noción remota de lo que es un presente sin memoria ni previsión; ni el amor ni la pasión, ni el viaje, ni la maravilla asumen la intensidad del tropel sensual de la infinita simultaneidad de estados del privilegiado del presente, prototípico, sin recuerdos ni presentimientos, sin sus inhibiciones o exhortaciones" (Fernández). 
Mör, aislado en una nave en forma de sandía con ventanas pintadas que no dan al exterior, no descubre nuevos mundos, planetas o sociedades utópicas que plantearían la promesa de un nuevo orden; descubre, sin embargo, una verdad ineludible:

La vida es siempre una broma: pero Mör tiene la ventaja de poderlo apreciar todo al mismo tiempo, de una sola mirada, o sea, sin fastidiosos altibajos de esperanzas y desilusiones. De todas formas es libre y dueño de sí mismo; como los muertos tiene la vida en sus manos. (66)

La perspectiva del outsider o "perspectiva estereoscópica", para usar un término del universo de Wilcock, representa la distancia, encarnada en la soledad, que separa al sujeto de la comunidad, y el mecanismo por medio del que se miran los dos polos del antagonismo, con la superposición del lente de la ironía. Una de las funciones del estereoscopio es la comparación de fotografías aéreas para analizar la cartografía geológica. La técnica estereoscópica provee a la imagen de los suplementos de distancia y profundidad, creando una perspectiva tridimensional que une dos imágenes en una, de la misma manera que la mirada irónica de los relatos de Wilcock desfamiliariza los dos polos del antagonismo de lo político.

Los viajeros y los monstruos de Wilcock revelan que toda comunicación con el otro es imposible; que toda vida en comunidad es insostenible. El hogar, el oikos como condición del viaje que garantiza su economía de ganancia o de pérdida, es una imposibilidad notada desde la escritura y que, al mismo tiempo, constituye una condición de la escritura. Como en el cuento "El etnógrafo" de Borges, no es posible escribir sobre el otro ni para el otro sin anular la esencia de la experiencia y de la escritura misma. En "La noche de Aix" Falcone ejercita ese desprendimiento fuera de la civilización; esa experiencia de la soledad profunda de la que, como el cenicero más malvado de Italia, el hombre tan delgado como una hoja de papel o Mör lanzado para toda la eternidad al espacio infinito, no se vuelve, porque no hay lugar físico o afectivo adonde volver:

Falcone se encontró de pronto con el primer café abierto. Entró como se vuelve de la alta montaña deshabitada y lejana o de un desierto de arena; como si se hubiera encontrado con el primer café abierto después del diluvio o de una explosión atómica ... el joven noctámbulo dio por terminada su prueba de iniciación ... [,] su ejercicio de desligamiento del ritmo social, primera jornada de inversión que con la ayuda de la suerte podría hacer de él un viajero sobre la tierra. $(143)^{13}$

13 Énfasis de la autora. 
La condición esencial del viajero se da en la inversión y el "desligamiento" del ritmo social. Este ejercicio, que solo es posible después de volver de una montaña deshabitada y lejana, de un desierto de arena, del diluvio o una explosión atómica, es el ejercicio de la escritura que se practica desde una insalvable distancia de la comunidad. Wilcock-Robinson escribe desde una isla desierta, no para reconstruir o recomenzar un mundo nuevo, sino para mirarlo con el estereoscopio que revela su profunda estupidez. Como señala el personaje-escritor Yves de Lalande: "La idea de escribir por sí solo una cosa tan compleja y variada como una novela, tan llena de humores y situaciones y puntos de vista diferentes, parecía más adecuada a un Robinson Crusoe" (La sinagoga de los iconoclastas 115). Tanto la metamorfosis como el viaje construyen un espacio distópico; una isla en la cual se evalúa(n) la historia (y la escritura misma) como ficción (y ficciones). La vida en comunidad es una broma vista desde afuera, desde arriba, desde un terreno baldío francés; una nave en forma de sandía observada desde los ojos de un hombre chato como una mariposa. Los lectores de Wilcock no podemos dejar de percibir lo absurdo de la historia tal como ocurrió, ya que sus personajes ponen en evidencia el lado siniestro de la comunidad, su falta o vacío; en palabras de Roberto Esposito:

para todas las filosofías la comunidad es un "pleno" o un "todo"... [.] O, por otra parte, con una terminología distinta solo en apariencia, la comunidad es un bien, un valor, una esencia que - según los casos - se puede perder y reencontrar como algo que nos perteneció en otro tiempo y que por eso podrá volver a pertenecernos. Como un origen a añorar o un destino a prefigurar. (Communitas 23)

La metamorfosis interrumpen la temporalidad de la comunidad: su proyección a futuro fundada en la utopía de progreso de la vida en sociedad. Después de todo, el futuro depende de la construcción de una voluntad colectiva o de una ideología comunitaria. El porvenir es siempre tan absurdo como el presente. Por eso el disc-jockey Nuno Tuno, convertido en una crisálida, colgando cabeza para abajo en un cuartito de la RAI, desempeña las funciones de falso oráculo, ya que "estas predicciones no siempre se cumplen y de todos modos se comprobó que a la gente no le gusta saber lo que va a pasar, sobre todo si luego no sucede" (El libro de los monstruos 138). La ironía de esta afirmación sugiere la incapacidad del lenguaje de representar algo que lo trascienda: que no sea más que el absurdo de la intención misma. Es así como el narrador afirma que Nuno Tuno "había anunciado la muerte del Presidente del Consejo y luego se comprobó que no estaba a punto de morir sino todo lo contrario" (138). ¿Qué es lo contrario de morir? En el caso de Nuno, transformarse; encarnar la irracionalidad de la vida en comunidad en la propia 
negación de la forma humana y en el aislamiento, colgando cabeza abajo en su cuartito "en espera de que algo salga de él" (138).

Los viajes y metamorfosis de estos personajes parecen repetir incansablemente la pregunta que formula Freud en su ensayo sobre lo siniestro: "what is the origin of the uncanny effect of silence, darkness and solitude?" (153). El origen de este efecto siniestro es precisamente la idea de una comunidad como origen o como mito: el mito de la plenitud de la comunidad en la escritura de Wilcock es un absurdo y un imposible. Por eso sus personajes están irremediablemente solos, en un viaje de ida que ha perdido el hogar porque, como afirma Borges en "Nueva refutación del tiempo", solo se pierde lo que realmente nunca se ha tenido.

\section{Obras citadas}

Amar Sánchez, Ana María. "Perdedores en Años de derrota.

Políticas de la memoria en la narrativa Rioplatense". Cuadernos

de literatura 16.31 (enero-junio 2012): 65-78. Impreso.

Anderson, Benedict. Imagined Communities. London: Verso, 1991. Impreso.

Arendt, Hannah. The Life of the Mind. New York: Harcourt

Brace \& Company, 1978. Impreso.

Avilés, Luis. "¿Qué significa pensar? Hannah Arendt y La vida del espíritu".

Filos 1 (2004): 11-24. Impreso.

Balderston, Daniel. "La literatura antiperonista de J. R Wilcock". Revista

Iberoamericana 52 (1986): 573-581. Impreso.

Balderston, Daniel. "Civilización y Barbarie: un topos reelaborado por J. R. Wilcock".

Discurso Literario 4 (1989): 57-61. Impreso.

Bloch, Ernst. The Utopian Function of Art and Literature. Trads. Jack Zipes y Frank

Mecklenburg. Cambridge: The MIT Press, 1996. Impreso.

Borges, Jorge Luis. Obras Completas. Buenos Aires: Emecé Editores, 2005. Impreso.

Boym, Svetana. The Future of Nostalgia. New York: Basic Books, 2001. Impreso.

Buck-Morss, Susan. Dreamworld and Catasthrophe.

Masachussetts: MIT Press, 2002. Impreso.

Derrida, Jacques. The Beast and the Sovereign. Vol. II. Eds. Michel

Lisse, Marie-Louise Mallet y Ginette Michaud. Chicago:

The University of Chicago Press, 2011. Impreso.

Esposito, Roberto. Confines de lo político. Nueve pensamientos sobre política. Trad.

Pedro Luis Ladrón de Guevara. Madrid: Editorial Trotta, 1996. Impreso.

Esposito, Roberto. Communitas: Origen y destino de la comunidad.

Madrid: Amorrotu, 2003. Impreso. 
Esposito, Roberto. Categorías de lo impolítico. Trad. Roberto Raschella. Buenos Aires: Katz, 2006. Impreso.

Fernández, Macedonio. "Cirugía de extirpación”. Uninstantedecaos. blogspot (20 de febrero de 2016). Web. 20 de febrero de 2016.

Giunta, Andrea. Avant Garde, Internationalism, and Politics: Argentine Art in the Sixties. Trad. Peter Kahn. Durham: Duke University Press, 2007. Impreso.

Herrera, Ricardo H. "Juan Rodolfo Wilcock y el problema de la restauración neoclásica". La ilusión de las formas. Buenos Aires: El imaginero, 1988. 53-78. Impreso.

Laclau, Ernesto. La razón populista. Buenos Aires: Fondo de cultura económica, 2005. Laclau, Ernesto y Chantal Mouffe. Hegemonía y estrategia socialista. Buenos Aires: Fondo de Cultura Económica, 2004. Impreso.

Laera, Alejandra. "Bestias, basura, vida (en la narrativa de Sergio Chejfec)". Cuadernos de literatura 16.31 (enero-junio 2012): 105-117. Impreso.

Mouffe, Chantal. On the political. New York: Routledge, 2006. Impreso.

Nancy,Jean-Luc. La comunidad desobrada. Trad. Pablo

Herrera. Madrid: Arena Libros, 2001. Impreso.

Perón, Juan Domingo. "Veinte verdades peronistas". Galeón (julio de 2013). Web. 20 de febrero de 2016.

Ronell, Avital. Stupidity. Chicago: University of Illinois Press, 2002. Impreso.

Schmitt, Carl. The Concept of The Political. Trad. George Schwab. Chicago: The University of Chicago Press, 1996. Impreso.

Van Den Abbeele, Georges. Travel as Metaphor. From Montaigne to Rousseau.

Minneapolis: University of Minnesota Press, 1992. Impreso.

Verón, Eliseo y Silvia Sigal. Perón o muerte: los fundamentos discursivos del fenómeno peronista. Buenos Aires: Eudeba, 2003. Impreso.

Wegner, Phillip. Imaginary Communities. Utopia, The Nation and The Spatial Histories of Modernity. Berkeley: University of California Press, 2002. Impreso.

Wilcock, Juan Rodolfo. El estereoscopio de los solitarios. Trad. Guillermo Piro. Buenos Aires: Sudamericana, 1998. Impreso.

Wilcock, Juan Rodolfo. Hechos inquietantes. Trad. Guillermo Piro. Buenos Aires: Sudamericana, 1998. Impreso.

Wilcock, Juan Rodolfo. El caos. Buenos Aires: Sudamericana / Barcelona: Editorial Anagrama, 1999. Impreso.

Wilcock, Juan Rodolfo. El libro de los monstruos. Trad. Ernesto Montequín. Buenos Aires: Sudamericana, 1999. Impreso.

Wilcock, Juan Rodolfo. La sinagoga de los iconoclastas. Trad. Joaquín Jordá. Barcelona: Editorial Anagrama, 1999. Impreso. 